\title{
COLOR POLLUTION CONTROL IN TEXTILE DYEING INDUSTRY EFFLUENTS USING TANNERY SLUDGE DERIVED ACTIVATED CARBON
}

\author{
Sajjala Sreedhar Reddy ${ }^{1 *}$, Bijjam Kotaiah ${ }^{2}$ and Nanaga Siva Prasad Reddy ${ }^{3}$ \\ ${ }^{1}$ Adama University, Faculty of Technology, Post Box No. 1888, Adama, Ethiopia \\ ${ }^{2}$ Sri Venkateswara University, Tirupati, Andhra Pradesh, India \\ ${ }^{1}$ Sri Venkateswara Engineering College, Chittoor, Andhra Pradesh, India
}

(Received November 28, 2007; revised August 4, 2008)

\begin{abstract}
Effective treatment of dyestuff containing textile dyeing industry effluents require advanced treatment technologies such as adsorption for the removal of dyestuffs. Powdered commercial coal based activated carbon has been the most widely used adsorbent for the removal of dyestuffs from dyeing industry effluents. As an alternative to commercial coal based activated carbon, activated carbon prepared from dried tannery sludge was used as an adsorbent for dyestuff removal from simulated textile dying industry effluent in this study. The color removal performance of tannery sludge derived activated carbon and commercial coal based activated carbon has been investigated using parameters such as adsorbent dosage, initial dye concentration, $\mathrm{pH}$ and temperature. It was found that tannery sludge derived activated carbon exhibits dye removal efficiency that is about $80-90 \%$ of that observed with commercial coal based activated carbon. The amount of dye adsorbed on to tannery sludge derived activated carbon is lower compared with commercial activated carbon at equilibrium and dye adsorption capacity increased with increase of initial dye concentration and temperature, and deceasing $\mathrm{pH}$. It was found that the Langmuir isotherm appears to fit the isotherm data better than the Freundlich isotherm. The leachate of heavy metals from tannery sludge derived activated carbon to the environment is very low, which are within the standard limit of industrial effluent and leachable substances.
\end{abstract}

KEY WORDS: Adsorption, Tannery sludge derived activated carbon, Commercial coal based activated carbon, Adsorption isotherms, TCLP

\section{INTRODUCTION}

Textile dyeing is a process in which clothing material is imparted the desired color(s)/shades by applying colorants (dyes) and host of organic/inorganic chemicals in aqueous media often at elevated temperatures and pressures in stages. In the textile dyeing process in addition to dyes large quantity of other organic/inorganic chemicals like electrolytes, carriers, leveling agents, promoting agents, chelating agents, emulsifying oils, softening agents etc. are also added. About 10 to $20 \%$ of the dye remains in the dye bath and is discharged along with other residual chemicals as exhausted dye bath waste. The exhausted dye bath wastes still contain significant quantities of coloring matter and impart color to the receiving water bodies. In addition to imparting color dye baths also contribute to organic and inorganic load of the receiving streams. Dye bath wastes are typically characterized by residual color, alkaline $\mathrm{pH}$ (mostly), excess TDS content, high COD but relatively low BOD values.

Coloration or discoloration of receiving water detracts attention, affects the appearance from aesthetic point of view and is dissented by public on presumption that the color is indicative of the pollution. Dyes are recognized as micro-toxicants and their acute and short-term effects have long been recognized. The complex organic framework of dyes and presence of heavy metals induce chronic toxicity and they may be mutagenic, teratogenic and carcinogenic. Many investigators reported several cases of tumors, cancer and effect on liver and kidney after longterm exposure. The most obvious impact of the discharge of dye colored effluent is the persisting nature of the color, which is stable and fast, difficult to degrade, toxic and inhibitory, and render the receiving water unfit for its intended use [1,2].

*Corresponding author. E-mail: ssreedharreddy@yahoo.com 
Various physical, chemical, physico-chemical and bio-chemical processes like sedimentation, equalization, neutralization, flotation, chemical oxidation/reduction, chemical precipitation, coagulation and flocculation, adsorption, ion exchange, reverse osmosis, electrochemical coagulation, etc. have been investigated for treatment of dye effluents [3-9]. Among all these processes, the adsorptive process is a sludge free process, and using activated carbon as a sorbent is found to be effective in removal of dye color and is firmly established as most reliable one [10].

Coal based activated carbon has been widely used as an adsorbent for the removal of various pollutants due to its high adsorption capacity [11-15]. However it has relatively high operational cost and problems of regeneration [16]. Therefore a number of non-conventional, low cost adsorbents have been tried for dye removal. These include bottom ash [17], fly ash [18, 19], coir pith [20], cassava peel [21], cotton [22], orange peel [23], bagasse fly ash [24], cellulose-based wastes [25], sewage sludge [26, 27], kaolinite [28], zeolite [29], wheat straw [30], sawdust [31, 32], char fines [33], oil shale and olive mill waste [34]. The adsorption process would provide an attractive technology, if the adsorbents were inexpensive and ready for use. Utilization of industrial solid waste for the treatment of wastewater is a win-win strategy because it not only converts the wastes in to useful materials but it also, alleviates the disposal problems. Further more it is not necessary to regenerate these cheap substitutes.

In this study, an activated carbon was prepared from dried tannery sludge, and studied for its potential use as an adsorbent for color removal from simulated cotton textile dyeing industry effluent with different parameters such as adsorbent dosage, initial $\mathrm{pH}$, contact time, temperature and initial dye concentration. The color removal efficiency of commercial coal based activated carbon (CAC) was also investigated and compared with the performance of tannery sludge derived activated carbon (TSC). The Langmuir and Freundlich isotherm models were used to represent the equilibrium data. The toxicity characteristics leaching protocol (TCLP) was used to study the leachability of toxic metals from tannery sludge derived activated carbon, to assess its applicability from environmental safety point of view.

\section{EXPERIMENTAL}

The dried and dewatered tannery sludge collected from sludge drying beds of a common effluent treatment for tannery effluents, Chennai, Tamil Nadu, India, was used for making the activated carbon using the procedure shown in Figure 1. The pyrolysis of the sludge was carried out in a muffle furnace in the absence of oxygen. The activation of pyrolized sludge was performed by impregnating $10 \mathrm{~g}$ of pyrolized sludge sample in to $25 \mathrm{~mL}$ of activating agent solution $\mathrm{ZnCl}_{2}(3$ M)) for 24 hours at room temperature. Later activating agent was drained and the wet activated carbon was dried at $105{ }^{\circ} \mathrm{C}$ for 24 hours. Before utilizing for adsorption studies, activated carbon sample was washed with distilled water to remove residual activating agents and dried at $105{ }^{\circ} \mathrm{C}$ in a hot air over for 24 hours. Characteristics of tannery sludge derived activated carbon in comparison with locally available commercial coal based activated carbon are presented in Table 1.

The simulated cotton textile dyeing industry effluent was prepared using Procion Brilliant Blue M-R (Figure 2) and other auxiliary chemicals as per the procedure suggested by Sreedhar Reddy et al., [35]. According to the information obtained from the local dyeing industries, usually $20 \%$ of the dyestuffs (hydrolyzed and/or unfixed form) and $100 \%$ of all assisting chemicals remain in the exhausted dye bath. Laboratory prepared dye-bath was suitably diluted to simulate the actual field conditions. The Composition of suitably diluted exhausted dye-bath is presented in Table 2 . 
Table 1. Properties of activated carbons used in the investigation.

\begin{tabular}{|c|l|l|l|}
\hline Activated carbon & Apparent density $(\mathrm{g} / \mathrm{L})$ & Iodine number & $\begin{array}{l}\text { Surface area } \\
\left(\mathrm{m}^{2} / \mathrm{g} \text { activated carbon }\right)\end{array}$ \\
\hline Tannery sludge derived & 788.5 & 998.431 & 999.03 \\
\hline Commercial coal based & 291.7 & 1249.753 & 1083.42 \\
\hline
\end{tabular}

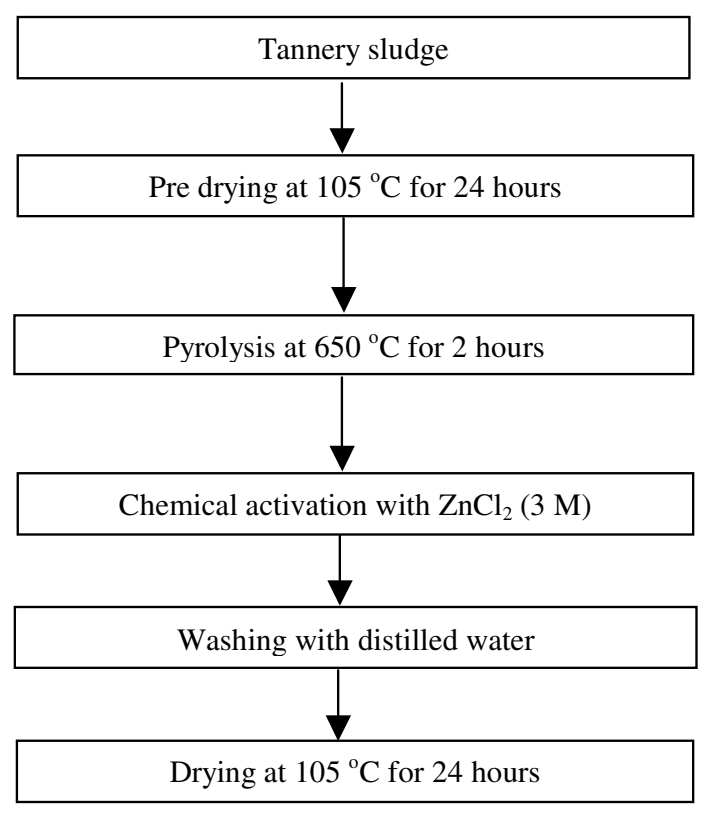

Figure 1. Schematic process flow diagram of activated carbon preparation from tannery sludge [27].

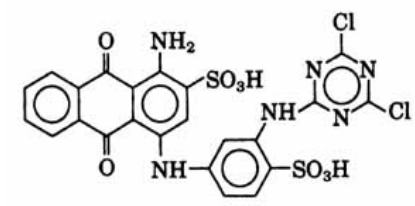

Figure 2. Chemical structure of Procion Brilliant Blue M-R.

Adsorption experiments were carried out by shaking $1.0 \mathrm{~g}$ tannery sludge derived activated carbon samples with $100 \mathrm{~mL}$ aqueous solution of simulated cotton textile dyeing effluent of desired concentrations at various initial dye concentrations and contact periods, $\mathrm{pHs}$ (3-11), and temperatures $\left(25\right.$ and $40{ }^{\circ} \mathrm{C}$ ) for $1 \mathrm{~h}$ (the time required for equilibrium to be reached between dyes adsorbed and dyes in solution). An incubator type shaker bath (Lab Net Scientific, India) was used to keep the temperature constant. The initial concentration of dye was varied from 120 $\mathrm{mg} / \mathrm{L}$ to $40 \mathrm{mg} / \mathrm{L}$ and the adsorbent dosage is varied from $1 \mathrm{~g} / \mathrm{L}$ to $10 \mathrm{~g} / \mathrm{L}$. All adsorption experiments were performed at $25{ }^{\circ} \mathrm{C}$ and $\mathrm{pH} 7.0$ of dye solution except those in which the effects temperature and $\mathrm{pH}$ were investigated. The $\mathrm{pH}$ of the solution was adjusted with $\mathrm{NaOH}$

Bull. Chem. Soc. Ethiop. 2008, 22(3) 
or $\mathrm{HCl}$ solution by using a $\mathrm{pH}$ meter. The $\mathrm{pH}$ meter was standardized with standard buffers before every measurement. At the end of the adsorption period, the solution was centrifuged for $15 \mathrm{~min}$ at $3000 \mathrm{rpm}$ and then the concentrations of the residual dye $\left(\mathrm{C}_{\mathrm{e}}\right)$ was determined with the aid of a Ultra-violet Visible Spectrophotometer (Spectronic, India) by measuring absorbance at $\lambda_{\max }$ of $602 \mathrm{~nm}$. Blanks containing no dyes were used for each series of experiments. Each experimental data was an average of two independent adsorption tests. The amounts of dyes adsorbed were calculated from the concentrations in solutions before and after adsorption. The data obtained from the adsorption tests were then used to calculate the adsorption capacity, $\mathrm{q}_{\mathrm{t}}$ (mg/g), of the adsorbent by a mass-balance relationship, which represents the amount of adsorbed dye per amount of dry adsorbent,

$\mathrm{q}_{\mathrm{t}}=\frac{\left(\mathrm{C}_{\mathrm{o}}-\mathrm{C}_{\mathrm{t}}\right) \mathrm{V}}{\mathrm{W}}$

where $\mathrm{C}_{\mathrm{o}}$ and $\mathrm{C}_{\mathrm{t}}$ are the concentrations of dye in solution $(\mathrm{mg} / \mathrm{L})$ at time $\mathrm{t}=0$ and $\mathrm{t}$, respectively, $\mathrm{V}$ the volume of the solution (liters), and $\mathrm{W}$ is the weight of the dry adsorbent used ( $\mathrm{g}$ ). The leaching characterization of tannery sludge derived activated carbon was evaluated using TCLP by suspending one gram of activated carbon in $20 \mathrm{~mL}$ of distilled water for 24 hours in an incubator shaker (Lab net scientific) at a rolling speed of $50 \mathrm{rpm}$. Later, distilled water was separated from the activated carbon using Whatman No. 40 filter paper and analyzed for heavy metals like chromium, cadmium, nickel and zinc using an atomic adsorption spectrophotometer as per the procedures suggested in standard methods for the examination of water and wastewater [36].

Table 2. Characteristics and composition of simulated cotton textile dyeing industry effluent.

\begin{tabular}{|c|l|c|}
\hline No & Parameter & Concentration \\
\hline 1 & Dye (Procion Brilliant Blue M-R) & 120 \\
\hline 2 & pH & 8.0 \\
\hline 3 & Total solids & 7500 \\
\hline 4 & Total suspended solids & 320 \\
\hline 5 & Total dissolved solids & 7180 \\
\hline 6 & BOD 5 at $20^{0} \mathrm{C}$ & 560 \\
\hline 7 & COD & 3200 \\
\hline 8 & Chlorides $\left(\right.$ as Cl$\left.^{-}\right)$ & 3800 \\
\hline 9 & Sodium $\left(\right.$ as $\left.\mathrm{Na}^{+}\right)$ & 7900 \\
\hline
\end{tabular}

All the values except $\mathrm{pH}$ are in $\mathrm{mg} / \mathrm{L}$.

\section{Effect of $p H$}

\section{RESULTS AND DISCUSSION}

Figure 3 shows the effect of $\mathrm{pH}$ on adsorption by TSC and CAC. Evidently $\mathrm{pH}$ significantly affected the extent of adsorption of dye over both the adsorbents. It was observed that the dye uptake by TSC and CAC was higher at lower $\mathrm{pH}$. At lower $\mathrm{pH}$ the surface of the adsorbents becomes positively charged and this would facilitate sorption of the color cation probably by exchange sorption [37]. The variances in solid phase aggregation of dye on activated carbon is probably due to interactions between the cationic groups on the dye molecule and the carboxyl, carbonyl, lactonic and quinone (acidic) and basic functional groups within the activated carbon structure [38]. Maximum uptake of dye was observed at $\mathrm{pH} 3.0$ on GAC and CAC. At an adsorbent loading of $1 \mathrm{~g} / \mathrm{L}$ the amount of dye adsorbed on TSC and CAC increased from 10 to $30 \mathrm{mg} / \mathrm{g}$ and from 12 to $40 \mathrm{mg} / \mathrm{g}$, respectively, with a decrease in $\mathrm{pH}$ from 11 to 3 . 
Effect of adsorbent dosage

Figure 4 shows the adsorption of dye from simulated textile dyeing industry effluent as a function of dosage of tannery sludge derived activated carbon and commercial activated carbon.

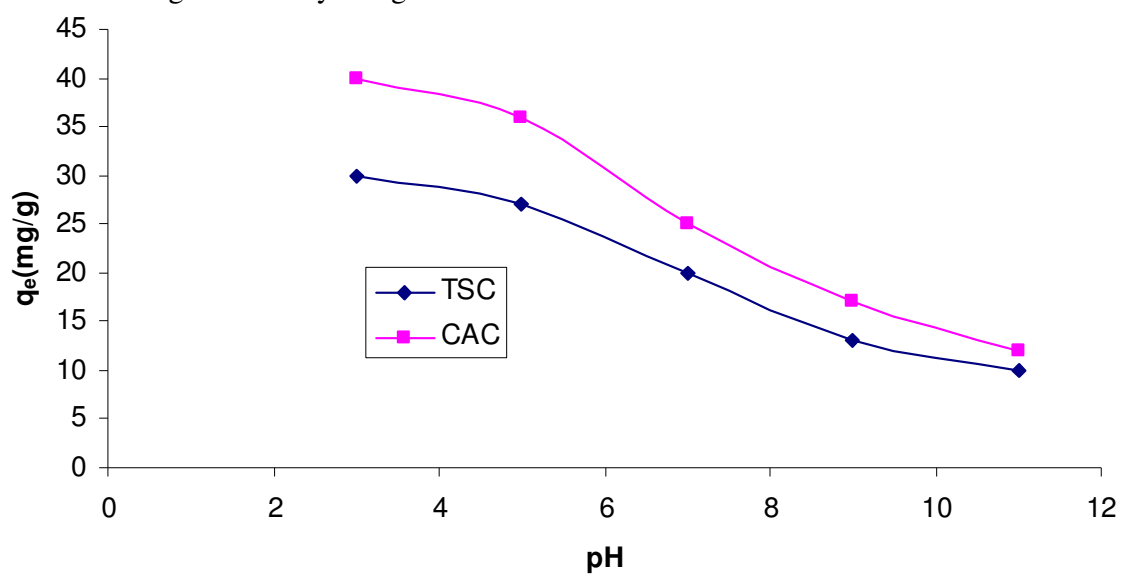

Figure 3. Effect of $\mathrm{pH}$ on adsorption capacities of tannery sludge derived and commercial activated carbons.

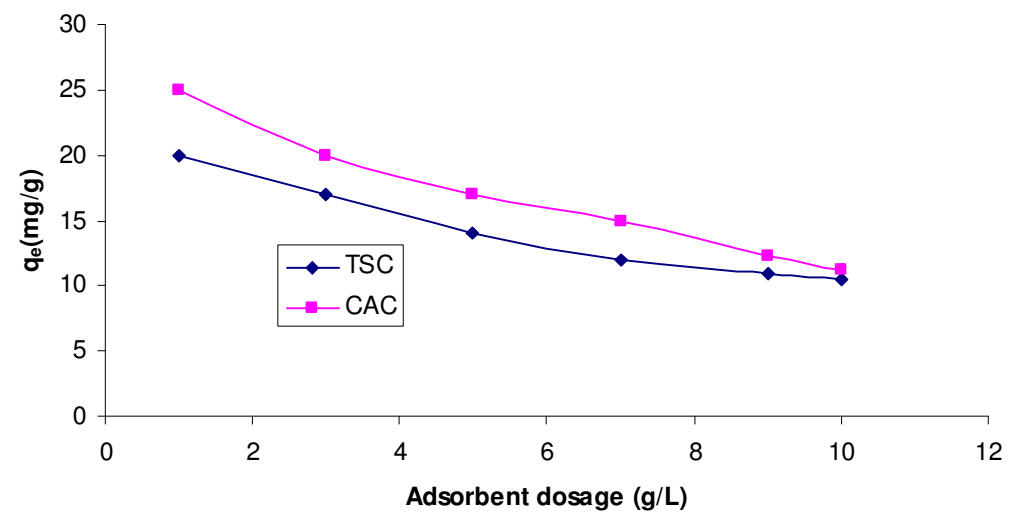

Figure 4. Effect of adsorbent dosage on adsorption capacities of tannery sludge derived and commercial activated carbons at equilibrium.

It is apparent that by increasing the adsorbent dose, the percentage dye removal increases, but adsorption density, the amount adsorbed per unit mass, decreases. It is readily understood that the number of available adsorption sites increases by increasing the adsorbent dose and it, therefore, results in the increase of percentage of dye adsorbed. The decrease in adsorption density with increase in the adsorbent dose is mainly because of unsaturation of adsorption sites through the adsorption process [37, 39]. Another reason may be due to the inter particle interaction, such as aggregation, resulting from high adsorbent dose. Such aggregation would lead to decrease in total surface area of the adsorbent and on increase in diffusional path length [37].

Bull. Chem. Soc. Ethiop. 2008, 22(3) 
Effect of contact time and initial dye concentration

Effects of contact time and initial dye concentration on adsorption of dye from simulate textile dyeing effluent by commercial activated carbon and tannery sludge derived activated carbon are presented in Figure 5 and 6. The amount of dye adsorbed increased with increase in contact time and almost reached equilibrium in $60 \mathrm{~min}$ for initial dye concentrations 40, 80, and $120 \mathrm{mg} / \mathrm{L}$ used in this study. The equilibrium time is independent of initial dye concentration. But in the first $30 \mathrm{~min}$, the initial rate of adsorption was greater for higher initial dye concentration, because the diffusion of dye molecules through the solution to the surface of adsorbents is affected by an increase in the dye concentration.

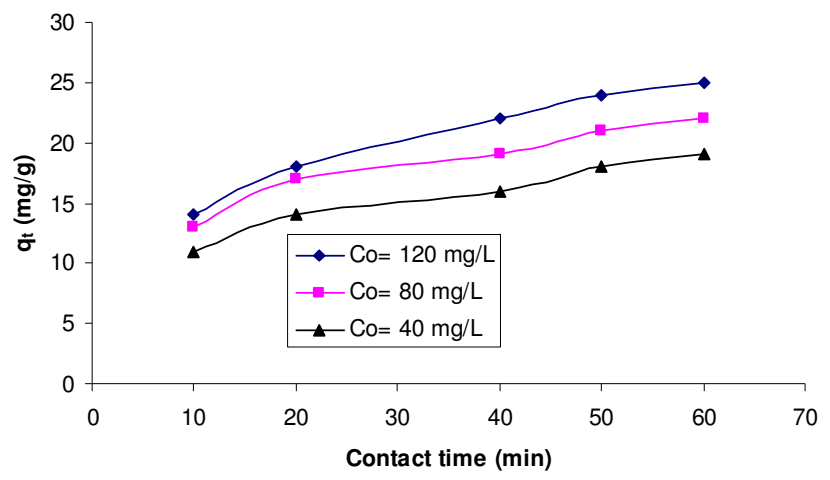

Figure 5. Effect of initial dye concentration and contact time on adsorption capacity of commercial activated carbon.

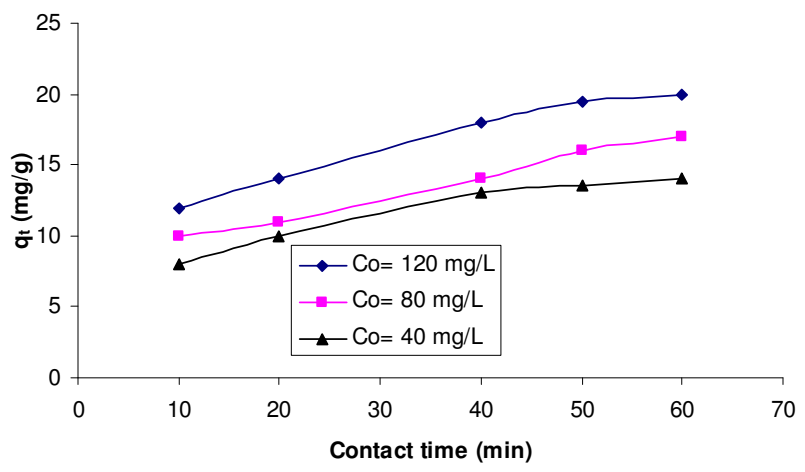

Figure 6. Effect of initial dye concentration and contact time on adsorption capacity of tannery sludge derived activated carbon.

An increase of the dye concentration accelerates the diffusion of dyes from the dye solution on to adsorbents due to the increase in the driving force of the concentration gradient $[40,41]$. Hence, the amount of dye adsorbed at equilibrium increased from 14 to $20 \mathrm{mg} / \mathrm{g}$ for tannery sludge derived activated carbon and from 19 to $25 \mathrm{mg} / \mathrm{g}$ for commercial activated carbon, as the initial dye concentration was increased from 40 to $120 \mathrm{mg} / \mathrm{L}$. 
Effect of temperature

It has been believed that the temperature generally has two major effects on the adsorption process. Increasing the temperature will increase the rate of diffusion of the adsorbate molecules across the external boundary layer and in the internal pores of the adsorbent particle, owing to the decrease in the viscosity of the solution. In addition, changing the temperature will change the equilibrium capacity of the adsorbent for a particular adsorbate [42]. Figure 7 shows the effect of temperature on adsorption capacities of tannery sludge derived and commercial activated carbons.

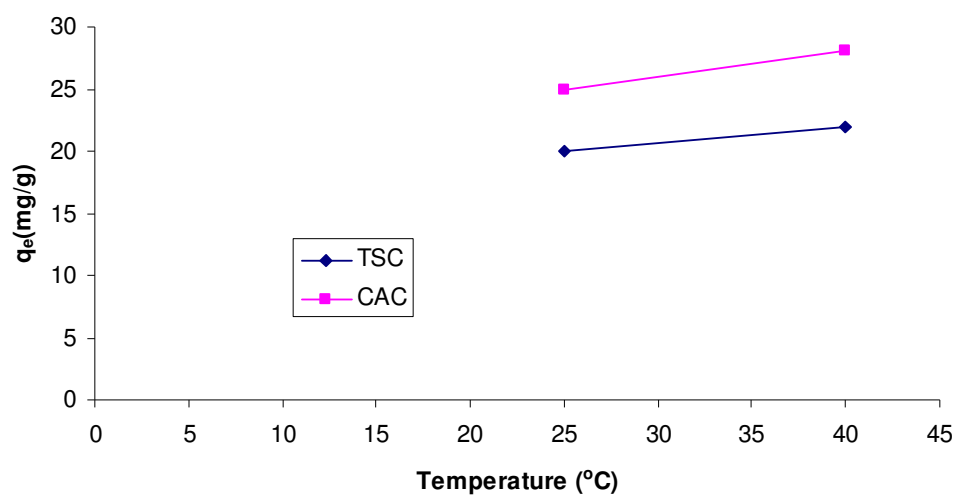

Figure 7. Effect of temperature on adsorption capacities of tannery sludge derived and commercial activated carbons.

It is seen that higher temperature will result in an increase in dye adsorption on tannery sludge derived and commercial activated carbons suggesting that the dye adsorption is an endothermic process. For tannery sludge derived activated carbon, the adsorption capacity at equilibrium is improved from $20 \mathrm{mg} / \mathrm{g}$ to $22 \mathrm{mg} / \mathrm{g}$ as the temperature of the experimentation is changed from $25{ }^{0} \mathrm{C}$ to $40{ }^{0} \mathrm{C}$. However, for commercial activated carbon, the adsorption capacity at equilibrium is increased from $25 \mathrm{mg} / \mathrm{g}$ to $28 \mathrm{mg} / \mathrm{g}$ for the change in experimentation temperature from $25{ }^{\circ} \mathrm{C}$ to $40{ }^{\circ} \mathrm{C}$.

\section{Adsorption isotherms}

The distribution of dye between the adsorbent and dye solution, when the system is at equilibrium, is important to obtain the capacity of the tannery sludge derived and commercial activated carbons. Table 3 summarizes the $\mathrm{Q}_{0}$ and $\mathrm{K}_{\mathrm{L}}$ values for the Langmuir isotherm, the $\mathrm{K}_{\mathrm{f}}$ and $\mathrm{n}$ values for the Freundlich isotherm and the correlation coefficients for the two isotherms. The Langmuir isotherm is represented by the following equation [43]:

$$
\mathrm{C}_{\mathrm{e}} / \mathrm{q}_{\mathrm{e}}=1 / \mathrm{Q}_{\mathrm{o}} \mathrm{K}_{\mathrm{L}}+\mathrm{C}_{\mathrm{e}} / \mathrm{Q}_{\mathrm{O}}
$$

where $\mathrm{q}_{\mathrm{e}}$ and $\mathrm{C}_{\mathrm{e}}$ are defined as the amount of dye adsorbed $\left(\mathrm{mg} \mathrm{g}^{-1}\right)$ and equilibrium liquidphase concentration $(\mathrm{mg} / \mathrm{L})$, respectively. $\mathrm{K}_{\mathrm{L}}$ is a direct measure of the intensity of the sorption $\left(1 \mathrm{mg}^{-1}\right)$, and $\mathrm{Q}_{0}$ is a constant related to the area occupied by a monolayer of adsorbate, reflecting the maximum adsorption capacity $\left(\mathrm{mg} \mathrm{g}^{-1}\right)$. From the data of $\mathrm{C}_{\mathrm{e}} / \mathrm{q}_{\mathrm{e}}$ vs $\mathrm{C}_{\mathrm{e}}, \mathrm{Q}_{0}$ and $\mathrm{K}_{\mathrm{L}}$ can be determined from the slope and intercept. The essential characteristics of Langmuir equation can 
be expressed in terms of a dimensionless separation factor $\mathrm{R}_{\mathrm{L}}$, which is defined by McKay et al. [44], as

$$
\mathrm{R}_{\mathrm{L}}=1 / 1+\mathrm{K}_{\mathrm{L}} \mathrm{C}_{\mathrm{O}}
$$

where $\mathrm{C}_{0}$ is any adsorbate concentration at which the adsorption is carried out. Favorable adsorption is indicated by $0<\mathrm{R}_{\mathrm{L}}<1$ [44]. The Langmuir isotherm constants were found to be $\mathrm{Q}_{0}=24.4 \mathrm{mg} \mathrm{g}^{-1}, \mathrm{~K}_{\mathrm{L}}=0.034 \mathrm{~L} \mathrm{mg}^{-1}$ for tannery sludge derived activated carbon $\left(\mathrm{R}^{2}=0.973\right)$, and $\mathrm{Q}_{0}=27.24 \mathrm{mg} \mathrm{g}^{-1}, \mathrm{~K}_{\mathrm{L}}=0.068 \mathrm{~L} \mathrm{mg}^{-1}$ for commercial activated carbon $\left(\mathrm{R}^{2}=0.9753\right)$.

The $R_{L}$ values for tannery sludge derived activated carbon were found to be between 0.59 and 0.196 for dye concentrations of 20,40,60,80,100 and $120 \mathrm{mg} \mathrm{L}^{-1}$ (data not shown in Table 3 ) and for the commercial activated carbon $R_{L}$ value is in between 0.42 and 0.109 for above said dye concentrations. The $\mathrm{R}_{\mathrm{L}}$ values between 0.59 and 0.196 show favorable adsorption of textile dyes on to tannery sludge derived activated carbon. The Freundlich isotherm, as an empirical equation has been shown to be satisfactory for low adsorbate concentrations. The Freundlich equation was linearized as follows:

$$
\log (\mathrm{X} / \mathrm{M})=\log \mathrm{K}_{f}+1 / \mathrm{n} \log \mathrm{C}_{\mathrm{e}}
$$

where $\mathrm{K}_{\mathrm{f}}$ and $\mathrm{n}$ are constants incorporating all factors affecting the adsorption process such as adsorption capacity and intensity, respectively. Values of $\mathrm{K}_{\mathrm{f}}$ and $\mathrm{n}$ were calculated from the intercept and slope of the plots of $\log (\mathrm{X} / \mathrm{M})$ versus $\log \left(\mathrm{C}_{\mathrm{e}}\right)$. From the slope and intercept of the best-fit lines, the following Freundlich isotherm constants were found for tannery sludge derived activated carbon and commercial activated carbon. $\mathrm{K}_{\mathrm{f}}=3.88 \mathrm{mg} \mathrm{g}^{-1}, \mathrm{n}=2.91$ for tannery sludge derived activated carbon $\left(\mathrm{R}^{2}=0.932\right)$ and, $\mathrm{K}_{\mathrm{f}}=5.86 \mathrm{mg} \mathrm{g}^{-1}, \mathrm{n}=3.23$ for commercial activated carbon $\left(\mathrm{R}^{2}=0.9689\right)$. The Freundlich exponent $\mathrm{n}$ for tannery sludge derived and commercial activated is in between 1 and 10 indicates favorable adsorption [45].

Table 3. Summary of the isotherm constants and correlation coefficients for Freundlich and Langmuir isotherms.

\begin{tabular}{|l|c|c|c|c|c|c|}
\hline Adsorbent & \multicolumn{3}{|c|}{ Freundlich isotherm } & \multicolumn{3}{c|}{ Langmuir isotherm } \\
\hline \multirow{3}{*}{ Tannery sludge derived } & $\mathrm{K}_{\mathrm{f}}$ & $\mathrm{n}$ & $\mathrm{R}^{2}$ & $\mathrm{Q}_{\mathrm{o}}(\mathrm{mg} / \mathrm{g})$ & $\mathrm{K}_{\mathrm{L}}(\mathrm{L} / \mathrm{mg})$ & $\mathrm{R}^{2}$ \\
\cline { 2 - 8 } & 3.88 & 2.91 & 0.932 & 24.4 & 0.034 & 0.9473 \\
\hline Commercial activated carbon & 5.86 & 3.23 & 0.9689 & 27.24 & 0.068 & 0.9753 \\
\hline
\end{tabular}

Leachate testing of tannery sludge derived activated carbon

The results of TCLP leaching test are presented in Table 4. Tannery sludge derived activated carbon generated leachate with values lower than the United States Environmental Protection Agency (EPA) requirements for the disposal of hazardous metals [46]. This is mainly due to the conversion of metals in the raw sludge to metal oxides during the pyrolysis. The results of TCLP tests indicated that activated carbons derived from tannery sludge are non-hazardous.

Table 4. TCLP of activated carbon derived from tannery sludge: contents of metals in leachate.

\begin{tabular}{|l|c|c|}
\hline Elements & Concentration in leachate $(\mathrm{mg} / \mathrm{L})$ & EPA regulatory level $(\mathrm{mg} / \mathrm{L})$ \\
\hline Chromium & 0.007 & 0.5 \\
\hline Nickel & 0.003 & - \\
\hline Zinc & 3.526 & 25 \\
\hline Cadmium & 0.035 & 1.0 \\
\hline
\end{tabular}




\section{CONCLUSIONS}

The results of the present investigation show that tannery sludge derived activated carbon has considerable potential for the removal of color from textile dying industry effluents over a wide range of concentrations. The adsorbed amount of dye increased as the surface area increased with an increasing adsorbent mass. The surface charge on the adsorbent and the solution $\mathrm{pH}$ play a significant role in influencing the capacity of an adsorbent towards dye ions. A decrease in the $\mathrm{pH}$ of solution leads to a significant increase in the adsorption capacities of dye on to commercial coal based activated carbon and tannery sludge derived activated carbon. The adsorbed amounts of dye increased with increase in contact time and reached the equilibrium in $60 \mathrm{~min}$. The equilibrium time is independent of initial dye concentration. The equilibrium data have been analyzed using Langmuir and Freundlich isotherms. The characteristic parameters for each isotherm and related correlation coefficients have been determined from graphs of their linear equations. It was found that the Langmuir isotherm appears to fit the isotherm data better than the Freundlich isotherm. The results of TCLP tests indicate that tannery sludge derived activated carbons generates leachate with values lower than the environmental protection agency (EPA) requirements for trace metals for disposal of hazardous materials and are considered as non-hazardous.

\section{AKNOWLEDGEMENTS}

The authors are thankful to the management of VIT University, Vellore, India for providing necessary facilities in conducting this research successfully.

\section{REFERENCES}

1. Lee, C.K.; Low, K.S.; Gan, P.Y. Environ. Technol. 1999, 20, 99.

2. Kadirvelu, K.; Kavipriya, M.; Karthika, C.; Radhika, M.; Vennilamani, N.; Pattabhi, S. Bioresource Technol. 2003, 87, 129.

3. Porges, R.; Horton, R.K.; Barty, H.G. Sewage Works J. 1939, 11, 827.

4. Jorgensen, S.V. Vatten. 1974, 4, 36.

5. Brandon, C.A. Nat. Water Supply Improvement J. 1990, 7, 39.

6. McKay, G. J. Chem. Tech. Biotechnol. 1982, 32, 759.

7. Barton, S.S. Carbon 1987, 25, 343.

8. Allen, S.J.; Khader, K.Y.H.; Bino, M. J. Chem. Tech. Biotechnol. 1995, 62, 11.

9. Venkata Mohan, S.; Karthikeyan, J. Environ. Pollution 1997, 97, 183.

10. Venkata Mohan, S. Ph.D. Thesis, Sri Venkateswara University, Tirupati, India; 1997.

11. Shukla, A.; Zhang, Y. H.; Dubey, P.; Margrave, J.L.; Shukla, S.S. J. Hazard. Mater. 2002, B95, 137.

12. Malik, P.K. Dyes and Pigments 2003, 56, 239.

13. Chiou, M.S.; Li, H.Y. Chemosphere 2003, 50, 1095.

14. Garg, V.K.; Gupta, R.; Yadav, A.B.; Kumar, R. Bioresource Technol. 2003, 89, 121.

15. Ozacar, M.; Sengil, I.A. J. Hazard. Mater. 2003, 98, 211.

16. Rozada, F.; Calvo, L.F.; Garcia, A.I.; Martin Villacorta, J.; Otero, M. Bioresource Technol. 2003, 87, 221.

17. Mukhtar, S.; Kenimer, A.L.; Sadaka, S.S.; Mathis, J.G. Bioresource Technol. 2003, 89, 217.

18. Kao, P.C.; Tzeng, J.H.; Huang, T.L. J. Hazard. Mater. 2000, 76, 237.

19. Janos, P.; Buchtova, H.; Ryznarova, M. Water Res. 2003, 37, 4938.

20. Namasivayam, C.; Kavitha, D. Dyes and Pigments 2002, 54, 47. 
21. Rajeshwarisivaraj, R.; Sivakumar, S.; Senthilkumar, P.; Subburam, V. Bioresource Technol. 2001, 80, 233.

22. Bouzaida, I.; Rammah, M.B. Matter. Sci. Eng. 2002, C21, 151.

23. Sivaraj, R.; Namasivayam, C.; Kadirvelu, K. Waste Manage. 2001, 21, 105.

24. Shaobin, W.; Huiting, L. Dyes and Pigments 2007, 72, 308.

25. Annadurai, G.; Juang, R.S.; Lee, D.J. J. Hazard. Mater. 2002, B92, 263.

26. Pan, S.C.; Lin, C.C.; Tseng, D.H. Resources Conservat. Recycling. 2003, 39, 79.

27. Sreedhar Reddy, S. Ph.D. Thesis, S.V. University, Tirupati, India; 2004.

28. Ghosh, D.; Bhattacharyya, K.G. Appl. Clay Sci. 2002, 20, 295.

29. Meshko, V.; Markovska, L.; Mincheva, M.; Rodrigues, A.E. Water Res. 2001, 35, 3357.

30. Robinson, T.; Chandran, B.; Nigam, P. Environ. Int. 2002, 28, 29.

31. Özacar, M.; Sengil, I.A. Process Biochem. 2005, 40, 565.

32. Garg, V.K.; Gupta, R.; Yadav, A.B.; Kumar, R. Bioresource Technol. 2003, 89, 121.

33. Mohan, S.V.; Chandrasekhar Rao, N.; Karthikeyan, J. J. Hazard. Mater. 2002, 90, 189.

34. Abu El-Shar, W.Y.; Gharaibeh, S.H.; Mahmoud, S. Environ. Geol. 1999, 39, 1090.

35. Sreedhar Reddy, S.; Kotaiah, B. Intern. J. Environ. Sci. Technol. 2005, 2, 245.

36. APHA; ANNA; WPCF Standard Methods for the Examination of Water and Wastewater, American Public Health Association, American Water Works Association and Water Pollution Control Federation: Washington, D.C.; 1989.

37. Mohan, S.V.; Karthikeyan, J. Clean Technology Environmental Policy 2004, 6, 196.

38. Walker, G.M.; Weatherley, L.R. Chemical Engineering J. 2001, 83, 201.

39. Yu, L.J.; Shukla, S.S.; Dorris, K, L.; Shukla, A.; Margrave, J.L. J. Hazard. Mater. 2003, B100, 3 .

40. Sun, G.; Xu, X. Ind. Eng. Chem. Res. 1997, 36, 808.

41. Özacar, M.; Sengil, I.A. J. Hazard. Mater. 2003, 98, 211.

42. Al-Qodah Z. Water Res. 2000, 34, 4295.

43. Namasivayam, C., Radhika, R., Suba, S. Waste Manage. 2001, 21, 381.

44. McKay, G. J. Chem. Tech. Biotechnol. 1982, 32, 759.

45. Sivaraj, R.; Namasivayam, C.; Kadirvelu, K. Waste Manage. 2001, 21, 105.

46. Federal Registrar (11798) Final Toxicity Characteristic Leaching Procedure (TCLP), Standards 40 CFR; 1990, 261, 24. 